Wicaksono, Rachel ORCID:

https://orcid.org/0000-0003-0312-8491 and Hall, Christopher J ORCID: https://orcid.org/0000-0001-9038-1238 (2020) Using ontologies of English. In: Hall, Christopher J ORCID: https://orcid.org/0000-0001-9038-1238 and Wicaksono, Rachel ORCID: https://orcid.org/0000-0003-0312-8491, (eds.) Ontologies of English.Conceptualising the language for learning, teaching, and assessment. Cambridge University Press, pp. 368-375

Downloaded from: http://ray.yorksj.ac.uk/id/eprint/4233/

The version presented here may differ from the published version or version of record. If you intend to cite from the work you are advised to consult the publisher's version: https://doi.org/10.1017/9781108685153.019

Research at York St John (RaY) is an institutional repository. It supports the principles of open access by making the research outputs of the University available in digital form. Copyright of the items stored in RaY reside with the authors and/or other copyright owners. Users may access full text items free of charge, and may download a copy for private study or non-commercial research. For further reuse terms, see licence terms governing individual outputs. Institutional Repository Policy Statement

\title{
RaY
}

Research at the University of York St John

For more information please contact RaY at ray@yorks.ac.uk 


\section{Using ontologies of English}

Rachel Wicaksono and Christopher J Hall, York St John University

In our introductory chapter we argued that applied linguistics must be more explicit about the ways in which English is conceptualised in and for the domains of language learning, teaching, and assessment. Now, after eighteen chapters which uncover, advocate, and contest beliefs about the nature of 'English' in a range of contexts and from a range of perspectives, we take stock of the project and consider its uses. We don't have the space here to reference all the arguments and evidence put forward by the authors of these chapters, but we will emphasise those points that we feel have helped to meet the aims of the book. Naturally, we give particular consideration to Pennycook's companion commentary in the previous chapter.

We start by reiterating the goals of the project. The seminar at York St John University which led to this book was not, of course, intended to 'settle' the ontological status of English, but rather to surface some of our existing conceptualisations, expose their similarities and differences, question the evidence on which our beliefs were based, and conceptualise anew. Given the choice to focus specifically on the entity we call 'the English language', and understandings of this entity in educational contexts, we sought to identify, interrogate, and ultimately shed light on these conceptualisations in ways which would potentially be useful to people working in relevant professional domains, especially teachers, materials writers, curriculum and test developers, and policy makers. The analysis was to be useful not in the sense of offering ready-made solutions to problems, but by providing prompts for reflection which could underpin actions in stakeholders' own educational contexts.

At the seminar, we proposed four key questions to guide the discussion, all of which were motivated by a desire to make theory useful:

1. How can an explicit focus and new thinking on ontologies of English challenge the monolithic assumptions pervading educational policy and practice?

2. What status and role should the concept of 'Standard English' have in language education?

3. To what extent are cognitively-oriented and social-oriented plurilithic approaches compatible?

4. What can scholars of L1 and L2 Englishes learn from each other in making explicit their ontologies of English?

Additionally, two general objectives were identified by the assembled delegates in the final discussion session as crucial ones for applied linguistics, again reflecting an impulse to be useful, to all stakeholders:

5. To reflect on what different ontologies of English imply for, and how they are shaped by, educational policy and practice, multilingualism, marginalised and dominant groups, and economic/political ideologies.

6. To take a more activist stance to challenge dominant monolithic conceptualisations of English, chiefly by promoting awareness of users' actual knowledge and practices, and the alternative ontologies that these imply. 
In what follows, our comments are framed by these original questions and objectives, and are made also in the light of the further project advocated by Pennycook in his chapter.

Pennycook (this volume) acknowledges the importance of thinking about ontological questions about English in the context of actual classrooms and learners. He argues that the separation of 'theoretical debate' from 'pragmatism' in the past has allowed ideas about 'what it is we are actually dealing with' to diverge in scholarly and professional contexts. This dangerous (and largely un-noticed) divergence of focus has, according to Pennycook, undermined the potential for useful collaboration between (scholarly) 'socio- and applied linguists' and (professional) classroom teachers. The theoretical linguists who traditionally engaged with ontological questions tended to conceptualise English and other named languages as abstract symbolic systems, independent of actual instantiations in minds and events; whereas teachers are surrounded by the actual speech, writing, or signs that reflect and create their environment and/but tend to think of named languages like English as single 'standard' linguistic codes which exclude 'non-standard' varieties and which are used best by their 'native speakers'. Hall (this volume) proposes a taxonomy of ways of thinking about 'the English language' which causally connects these different ideas, traces their history, and considers their consequences. Chapters in Parts B, C, and D reflect on what different ontologies of English imply for, and how they are shaped by, educational policy and practice; and chapters in Parts $E$ and $F$ focus on how new thinking might challenge traditional assumptions about 'English' in broader domains.

Pennycook's uses of the term theoretical in 'theoretical linguistics' and 'theoretical debate' highlight an enduring and important challenge for applied linguistics. The first use creates a contrast with applied linguistics, in which debates about language are rooted in the 'real world' context of English language education, as opposed to 'theoretical linguistics' which is characterised as being devoted to the description of an imagined abstraction. 'Theoretical debate', on the other hand, implies a critical discussion of ideas, assumptions, and beliefs in order to better understand why the 'real world' is (thought to be) as it is. As Pennycook suggests, and as this book demonstrates, 'theoretical debate' has (belatedly) commenced in applied linguistics, with practitioners, and scholars who work closely with them, asking themselves questions about the nature of the conceptual entity they are teaching and testing, and how this entity relates to the multilingual practices unfolding in the globalised world around them.

The collection and analysis of empirical data has demonstrated what many language teachers have always known: that learning and using 'English' in the classroom (inevitably for L2 and regularly also for L1) occurs as part of a multilingual environment, whether this is manifested only cognitively/internally or also socially/interactively. The complex plurilingual patterning of a typical language classroom challenges traditional boundaries between languages, and between language and other ways of communicating. In many cases, teachers have developed strategies to resist the use of other languages beyond the target one (demanding or pleading with their students to speak English only, for example) but have embraced the blurring of boundaries between language and other forms of semiosis (often using pictures, drawings, gestures and facial expressions to convey meaning). Evidence of English language use outside the classroom has confirmed that what we are actually dealing with is communication via a multilingual/multimodal, hybrid blend of sociocultural artefacts. Chapters in part B and E of this book use evidence of actual language use in classroom and 
lingua franca contexts to help work out 'what it is we are actually dealing with' in these environments, and touch on the extent to which cognitively-oriented and socially-oriented plurilithic approaches are compatible.

Pennycook (this volume) rightly highlights the usefulness of ontological analysis for related questions about why we value some (varieties/uses of) language(s) more highly than others. These beliefs about language (language ideologies) help to explain why English is part of complex local contexts of power and struggle for power. Thus, careful consideration of what 'English' is, can undermine assumptions about why (some versions and some uses of) 'it' is perceived as better than others. Thinking about ontologies, and then working our way towards thinking about ideologies, has the potential practical application of pointing to action, as chapters in parts $C$ and $D$ of this book show. In this way, we can create opportunities for a more activist stance to challenge dominant monolithic conceptualisations of English, in the learning and teaching contexts in which we work-an example of the potential practical use of 'theory'. So the two questions about what (people believe) English is (ontology) versus what English does (ideology) are indeed related, in that it helps to know what we mean by 'English' before we explore the consequences of our understanding(s) of it in practice. But the questions are (obviously) different: it is, we believe, legitimate to consider the ontological status of English as a separable component in the analysis of related ideologies (cf. Sharpe, 1974; Hall and Cunningham, in prep.).

Discussions of ideological, epistemological, and ontological issues in applied linguistics have frequently gone hand-in-hand with criticism of cognitive approaches to language (e.g. Firth and Wagner, 1997; Thorne and Lantolf, 2007; Pennycook, 2010, this volume; Canagarajah, 2013 , this volume). It is argued that 'representational' views of language are antithetical to, rather than complementary with, those in which language is conceptualised as social practice. Languages as symbolic systems are seen as artefactual, only emerging from social practice, rather than as dynamic resources which also feed into it. Linguistic resources are seen as inseparable from other semiotic resources, rather than as ontologically distinct yet only meaningful when embedded in social practice. It is hard to reconcile such beliefs with the abundant evidence from cognitive neuropsychology for the systematic and perduring (but mutable) representation of language resources in individual long-term memory and their independent contribution to meaning-making in use. Take, for example, the consistent and compelling data from neuroimaging studies in recent decades. Measurements of neural activity such as event-related potentials (ERPs) have isolated patterns such as the so-called 'N400' peak, which is reliably observed in cases where individuals experience semantically inappropriate words in utterances (e.g. bake in The cats won't eat/bake the food Mary leaves them), but not in the case of incongruities with non-linguistic input (e.g. music) or with grammatical or phonological incongruities (Kutas and Federmeier, 2000). A second and contrasting characteristic neural pattern is the P600 peak, which is triggered by grammatically (as opposed to semantically) anomalous words in utterances (e.g. eating in The cats won't eat/eating the food Mary leaves them; Osterhout and Holcomb, 1992). Studies of mental operations involving different kinds of resources (linguistic and nonlinguistic) also demonstrate the involvement of neural substrates which are distinct for modality (e.g. Monti et al., 2012, on language vs. algebra). Such evidence is strongly suggestive of coordinated brain processes which are associated uniquely with linguistic, rather than other semiotic, resources. 
To such 'double dissociations' in processing by unimpaired language users can be added cases of selective impairment or loss, in which one component or feature of language is affected and another spared. Examples include: (a) people with aphasia who have impairments which selectively affect either verbs or nouns, but are not attributable to semantic features (Luzzatti et al., 2016); (b) dissociations in production between impaired access to the 'mental dictionary' in Alzheimer's Disease, and to the 'mental grammar' in Parkinson's Disease (Ullman et al., 1997); (c) dissociations in ability to use recursion (embedding one thing in a thing of the same type) in language (e.g. sentence embedding like My dog [chased the cat [which ate the cheese]]]) but not in logical reasoning (e.g. perspective embedding like To my surprise, she was happy), and vice-versa (e.g. in people with aphasia vs. people with Alzheimer's Disease: Bánréti et al., 2016). Taken together these abilities and disabilities strongly suggest that the basic constructs of theoretical linguistics (syntax, rules [as regularities], words, verbs, nouns, embedded clauses, etc.) have physical correlates in brains which can be distinguished from those which pertain to general systems of meaning, reasoning processes, or other semiotic processing domains. It is this set of cognitive resources that Hall (this volume) refers to as the LANGUAGE CAPACITY and, with other resources and processes, underpins LANGUAGING.

In her review of perceived incompatibilities between the fields of Second Language Acquisition and World Englishes, Ortega (2018, p. 69) points out that the former does not preclude a social-cultural understanding of English (or other languages learnt after the first). Furthermore, pointing to usage-based linguistics (cf. Eskildsen, this volume), she correctly observes that there is no need for a view of language as social practice to preclude simultaneous focus on its cognitive status in individuals. Indeed, we would argue that usagebased approaches provide a theoretical framework in which the two perspectives can be fruitfully combined-in other words, there is no need to choose between them. English is both social practice and (sedimented) mental resource. Returning to the inevitable 'pragmatism' of applied linguistics, we recognise another reason why cognitively-oriented perspectives, when formulated in usage-based terms, can be useful to practitioners involved in English learning, teaching, and testing. This is the reality that the linguistic resources of English tend to be developed (L2) or extended (L1) by learners in classroom contexts, and that the resources needed and/or expected will typically involve exonormative (effectively $\mathrm{N}$-LANGUAGE) constraints (cf. Harder, this volume). To be able to contest the ideologies underpinning this orthodoxy, practitioners need ways of understanding learning which don't dismiss or marginalise the necessity of grammar (as regularity rather than regulation), and other linguistic resources, in LANGUAGING.

As we said at the beginning of this chapter, our aim in the York St John seminar and in this book was to identify and interrogate conceptualisations of English in ways which were potentially useful to people working in relevant professional domains, especially teachers, materials writers, curriculum and test developers, and policy makers. For actual solutions to specific problems to be successful, they need to be designed from the bottom up, by the people experiencing the problem (Widdowson, 1990). Hence, rather than offering solutions, we aimed to provide accessible and relevant prompts for reflection; reflection which could, and should, impel appropriate and timely actions in specific educational contexts (Pollard, 2002). While we agree that there are many interesting and useful questions about what 
English is thought to be, and thought to do, in other contexts (Pennycook, this volume), in order to maximise the usefulness of our discussion to teachers, materials writers, curriculum and test developers, and policy makers, we necessarily focused on educational contexts.

In a previous publication, we considered the usefulness of engaging in philosophical reflection for language professionals, specifically lexicographers dealing with the objective nature and existence of words, suggesting that (unlike theoretical linguists), “...applied linguists can't afford to be detained by ontological questions" (Hall et al., 2017, p. 249). Even in the very short space of time between writing that claim and this conclusion, our ideas about the usefulness of ontological questions for language professionals have changed-if not substantially, then at least in emphasis. While lexicographers, teachers, and other language professionals all have their day jobs to do, we think reflection on 'what it is we are actually dealing with' should also form part of what they regularly do. Of course, English teachers have to teach English, but there is no avoiding an idea of what 'English' is, whether or not they find time to identify and interrogate their corresponding ontological commitments. So on reflection, "detain" sounds too negative. In order to avoid the separation of 'theoretical debate' from 'pragmatism' that has allowed ideas about 'what it is we are actually dealing with' to diverge in scholarly and professional contexts (Pennycook, this volume), we now advocate that all language professionals should reflect on (versions of) the questions posed at the beginning of this chapter. Furthermore, we think that there is value for language professionals in working with stakeholders (students, test takers and individuals affected by English language policy-making, for example), to surface their ontologies of English and explore areas of overlap, contradictions, and the practical implications of their theories.

How best to do this is the subject of another book.

\section{References}

Bánréti, Z., Hoffmann, I., and Vincze, V. (2016). Recursive subsystems in Aphasia and Alzheimer's Disease: case studies in syntax and Theory of Mind. Frontiers in Psychology, 7, 405.

Canagarajah, S. (2013). Translingual practice: Global Englishes and cosmopolitan relations. London: Routledge.

Firth, A., and Wagner, J. (1997). On discourse, communication, and (some) fundamental concepts in SLA research. The Modern Language Journal, 81(3), 285-300.

Hall, C. J. and Cunningham, C. (in prep.). Educators' beliefs about English and languages beyond English: from ideology to ontology, and back again.

Hall, C. J., Smith, P. H. and Wicaksono, R. (2017). Mapping applied linguistics: A guide for students and practitioners. London: Routledge.

Kutas, M. and Federmeier, K. D. (2000). Electrophysiology reveals semantic memory use in language comprehension. Trends in Cognitive Sciences, 4, 463-470.

Luzzatti, C., Aggujaro, S. and Crepaldi, D. (2006). Verb-noun double dissociation in aphasia: theoretical and neuroanatomical foundations. Cortex, 42(6), 875-883.

Monti, M. M., Parsons, L. M., and Osherson, D. N. (2012). Thought beyond language: neural dissociation of algebra and natural language. Psychological Science, 23(8), 914-922. 
Ortega, L. (2018). Ontologies of language, Second Language Acquisition and world Englishes. World Englishes, 37, 64-79.

Osterhout, L., and Holcomb, P. J. (1992). Event-related brain potentials elicited by syntactic anomaly. Journal of Memory and Language, 31(6), 785-806.

Pennycook, A. (2010). Language as a local practice. London: Routledge.

Pollard, A. (2002). Reflective teaching: Effective and evidence-informed professional practice. London: Continuum.

Sharpe, R. A. (1974). Ideology and ontology. Philosophy of the Social Sciences, 4, 55-64.

Thorne, S. L., and Lantolf, J. P. (2007). A linguistics of communicative activity. In S. Makoni and A. Pennycook (eds), Disinventing and reconstituting languages (pp. 170-195). Clevedon: Multilingual Matters.

Ullman, M. T., Corkin, S., Coppola, M., Hickok, G., Growdon, J. H., Koroshetz, W. J., and Pinker, S. (1997). A neural dissociation within language: Evidence that the mental dictionary is part of declarative memory, and that grammatical rules are processed by the procedural system. Journal of Cognitive Neuroscience, 9(2), 266-276.

Widdowson, H. G. (1990). Aspects of language teaching. Oxford: Oxford University Press. 